\title{
O MUNICÍPIO E A SEGURANÇA PÚBLICA: PARA COMPREENDER O PRESENTE, UM RETORNO AO PASSADO
}

\section{THE CITY AND THE PUBLIC SECURITY: IN ORDER TO UNDERSTAND THE PRESENT, A RETURN TO THE PAST}

${ }^{1}$ Leticia Fonseca Paiva Delgado

\section{RESUMO}

Partindo da percepção de novos formatos organizacionais na área da segurança pública principalmente após a promulgação da Constituição Federal de 1988 - que se alinham com a busca de novas formas de controle da violência urbana, o objetivo principal deste artigo é compreender o processo de inclusão do município nos debates sobre a gestão das políticas de segurança pública dentro do contexto brasileiro atual. A realização de uma pesquisa bibliográfica, através da abordagem qualitativa, pretende, ao perceber o fenômeno a partir de sua abordagem histórica, apresentar os paradigmas denominados Segurança Nacional, Segurança Pública e Segurança Cidadã, por se relacionarem diretamente com a temática central.

Palavras-chave: Segurança pública, Município, Violência urbana, Segurança nacional, Segurança cidadã

\begin{abstract}
From the historical perspective of new organizational formats in the area of public security especially after the promulgation of the Federal Constitution of 1988 -, which align with the search for new forms of management of urban violence, the main purpose of this article is to understand the city's inclusion process in the debates on the management of public security policies in the current Brazilian context. Carrying out a literature search, through a qualitative approach, will seek - from understanding the phenomenon from a historical perspective - to introduce paradigms named National Security, Public Safety and Citizen Security, which are directly related to the central theme.
\end{abstract}

Keywords: Public security, City, Urban violence, National security, Citizen security

\footnotetext{
${ }^{1}$ Doutoranda em Sociologia e Direito pela Universidade Federal Fluminense - UFF, Niterói - RJ (Brasil) Professora do Instituto Doctum de Educação e Tecnologia - DOCTUM, Minas Gerais (Brasil).

E-mail: lfpdelgado@ hotmail.com
} 


\section{INTRODUÇÃO}

Creio que é preciso ter a modéstia de dizer que, por um lado, o momento em que vivemos não é esse momento único, fundamental ou irruptivo da história a partir do qual tudo termina e tudo recomeça; é preciso ter a modéstia de dizer, ao mesmo tempo, que - mesmo sem esta solenidade - o momento em que vivemos é muito interessante, e precisa ser analisado, decomposto e que, com isso, temos que nos colocar a questão: o que é o hoje? (Michel Foucault)

Sem dúvida, as questões correlatas ao aumento da violência urbana, principalmente após a década de 1990, trouxeram consequências nos planos simbólico, econômico e político. Enquanto o povo festejava as tímidas conquistas da reabertura democrática, a criminalidade se estruturava enquanto um problema público que gradativamente ocupava o centro das preocupações das regiões metropolitanas brasileiras. À expectativa de que as cidades contemporâneas seriam espaços de civilidade, segurança e fortalecimento dos laços de solidariedade, contrapõe-se a generalização da percepção destes espaços como ambientes violentos, em que sentimentos relacionados ao temor da vitimização são disseminados e trazem consequências nos planos individual, coletivo e político. A ideia de que a insegurança urbana produz efeitos no plano político é fortalecida por especialistas que defendem que "os problemas ligados à área da segurança pública são politizados à medida que a legitimidade dos governos é predominantemente determinada por sua capacidade de manter a ordem e uma possível paz social" (BARREIRA, 2004, p. 77).

Neste contexto, em que as delimitações constitucionais e o discurso da ausência de responsabilidade deixam de satisfazer o eleitorado, a segurança pública entra na agenda municipal. É a construção de um novo formato organizacional e institucional que destina ao município - enquanto ente federado - um papel central nos debates sobre gestão da violência urbana.

A presente pesquisa - de cunho exploratório - visa compreender o processo de reconhecimento do município como ente central nas discussões sobre a gestão segurança pública no Brasil. Em decorrência da abordagem escolhida, o estudo pautou-se, fundamentalmente, na necessidade do conhecimento do processo histórico de construção dos discursos oficiais sobre as políticas de segurança no Brasil, bem como à razão de esses terem assumido os contornos atuais, para um melhor entendimento do fenômeno.

Trazer o município para o epicentro das discussões sobre a responsabilidade e/ou efetividade das políticas de segurança pública impõe a identificação de alguns dos contornos 
político-administrativos que a questão assumiu ao longo da história brasileira. Tomando-se como referência a Constituição Federal de 1988, notadamente o seu artigo 144, constata-se que a compreensão da interface entre município e segurança pública se faz também pelo reconhecimento da centralidade que as instituições policiais e as políticas repressivas sempre tiveram na gestão da "ordem pública".

Apesar de uma nova ordem constitucional vigente - fruto do processo de redemocratização vivenciado no País - são recorrentes as sinalizações no sentido de que a Constituição Federal de 1988 teria rompido apenas formalmente com o regime autoritário até então vigente. A manutenção das estruturas autoritárias das instituições policiais, fortalecidas durante duas décadas de ditadura militar, seria um dos fatores que dificultaria a modificação de uma lógica estatal fortemente penalizadora e a consolidação de uma política de segurança pública cidadã, dentro da qual o município tem um papel central.

A fim de buscar soluções para a problemática principal, procedeu-se a realização de uma pesquisa bibliográfica que, através da abordagem qualitativa, buscou compreender o fenômeno a partir, principalmente, de seu acontecer histórico. A construção teórica, que se pautou principalmente por levantamento bibliográfico sobre a temática da segurança pública, evidenciou um consenso de que novos discursos sobre as políticas de segurança pública encontram o desafio de se fortalecerem dentro de um contexto histórico em que a gestão da “ordem pública” foi efetivada, quase que exclusivamente, pelo viés repressivo.

O objetivo principal deste artigo é compreender o processo de inclusão do município nos debates sobre a gestão das políticas de segurança pública dentro do contexto brasileiro atual. Delineada a finalidade principal deste trabalho, o primeiro objetivo específico será traçar a relação existente entre o aumento da criminalidade no Brasil e o fortalecimento de novos discursos no campo da segurança pública. Em segundo lugar, buscar-se-á apresentar os diversos paradigmas de segurança existentes no Brasil, bem como situar a discussão dentro do contexto normativo trazido pela Constituição Federal de 1988 e diplomas legais subsequentes. Por fim, a pertinência da abordagem histórica para a compreensão do problema apresentado também será verificada.

O artigo está estruturado em dois capítulos essencialmente teóricos. O primeiro visa apresentar as discussões sobre o aumento da criminalidade pós década de 1980 e a relação destes com novos formatos organizacionais sobre as políticas de segurança pública. O segundo será destinado à apresentação dos paradigmas de segurança pública existentes no Brasil e suas relações com a discussão principal. 


\section{OS DEBATES SOBRE O AUMENTO DA CRIMINALIDADE PÓS DÉCADA DE 80}

Quando o povo unido comemorava as pequenas conquistas da democracia no inicio dos anos 80, não poderia imaginar que outros problemas por vir seriam tão mais difíceis e ardilosos a ponto de confundi-lo e desuni-lo nas décadas seguintes. (ZALUAR, 1998, p. 246).

No Brasil, principalmente nas décadas de 1980 e 1990, as discussões sobre o aumento da criminalidade se acentuaram. O tema da Segurança Pública passa a integrar as agendas social e política brasileiras, passando a fazer parte das conversas cotidianas nas casas, nas ruas, no comércio, bem como em todos os canais de televisão e rádio. A priori, tal fato pode ser relacionado ao considerável aumento da criminalidade nos centros urbanos.

Paradoxalmente, tal inquietação ocorreu simultaneamente a um intenso debate sobre o processo de redemocratização. Após um longo período de autoritarismo, ressurgia a sensação de que o País teria efetivas condições sociais e institucionais que viabilizassem aos cidadãos a participação ativa na formação do governo e nos mais diversos aspectos da vida social.

Apesar de Frey e Czajkowski (2005) apontarem para as escassas informações produzidas e compartilhadas com a sociedade civil no campo da segurança pública durante o período ditatorial, a fim de contornarem os argumentos tendentes a relacionar o processo de deteriorização progressiva e intensa da ordem pública nos centros urbanos desde 1980 e o processo de consolidação das instituições democráticas, no plano empírico verificamos que pesquisas reforçaram o aumento exponencial da criminalidade no Brasil nas últimas 20 (vinte) anos.

Segundo a Organização Panamericana de Saúde (Paho), o Brasil, entre 1996 a 1999, atribuiu 35,6\% das suas mortes externas a homicídios, percentagem bem significativa em comparação aos outros países do continente Americano pesquisados. Em relação à vitimização juvenil, de acordo com a mesma pesquisa, o Brasil ocupou o primeiro lugar em mortes por homicídios de jovens entre 15 a 24 anos. Segundo o Mapa da Violência de 2013, em um período de 30 (trinta) anos, observamos um aumento percentual de $414 \%$ de óbitos em virtude de agressões por arma de fogo entre os jovens de $\underline{15 \text { a } 29}$ anos no Brasil. Dentro desta faixa, em 1980 o SIM - Subsistema de Informação sobre Mortalidade - contabilizou 4.415 óbitos, contra 22.694 em 2010 (WAISELFISZ, 2013). O Mapa da Violência 2014 também 
traz dados preocupantes. De 1980 a 2011, tivemos, no Brasil, 1.145.908 mortes por homicídios. Em 1980, foram 13.910 mortes por esta causa. Ao comparar esse índice ao número de 52.198 homicídios em 2011, a variação foi de $275,3 \%$.

A partir da década de 90, a violência e suas consequências, passam a ser objeto de reflexão por outras áreas do saber, dentre as quais a saúde pública. Minayo e Souza (1993) afirmam que devido à mudança do perfil epidemiológico dos óbitos, as "doenças de desenvolvimento" - que assumiram o papel principal dentre as causas de mortalidade na década de 80 - perderam sua centralidade, em virtude dos elevados índices de acidentes de trânsito e homicídios.

Tal como numa epidemia, todos são afetados pela fonte comum de uma estrutura social desigual e injusta, que alimenta e mantém ativos os focos específicos de violência, os quais se expressam nas relações domésticas, de gênero, de classe e no interior das instituições (MINAYO, SOUZA, 1993, p.65-66 ).

No Brasil, foram contabilizados, no período de 2008 a 2011, um total de 206.005 vítimas de homicídios, número bem superior quando comparado aos números dos 12 maiores conflitos armados acontecidos no mundo entre 2004 e 2007. (WAISELFISZ, 2014). Com a taxa de 27,4 de homicídios por 100 mil habitantes, comparativamente, o país ocupa a sétima posição no conjunto dos 95 países mais violentos do mundo, segundo dados fornecidos pela OMS e analisados nos períodos compreendidos entre 2007 e 2011.

Através dos dados comparativos trazidos pelo Mapa da Violência 2014, Walselfisz (2014) aponta para algumas características da violência no Brasil. Os processos de disseminação e interiorização teriam causado o deslocamento da violência de municípios de grande porte - acima de 100 mil habitantes - para municípios de pequeno e médio porte. Dentre os fatores impulsores da mudança da "interiorização" do fenômeno, o autor cita as deficiências e insuficiências do aparelho de segurança em áreas de baixos níveis de violência. Esse deslocamento seria responsável, não somente pela disseminação da violência homicida ao longo do território nacional, como também por uma nova geografia do crime, a demandar do poder público novas formas para seu enfrentamento.

A pesquisa realizada pelo DataFolha entre 1996 a 2000, citada por Adorno (2003), clarificou a crescente preocupação da população com a temática da segurança pública. A esfera pública, agora midiatizada, passa a ser percebida como grande fator de pressão política, a reclamar maior presença do governo federal na resolução de problemas relacionados à aplicação da lei e da ordem. A relação entre aumento de criminalidade e medidas repressivas passa a ser publicizada, sendo que a segunda aparece como solução salvadora para a primeira. 
A impossibilidade estatal de dar vazão a toda demanda punitivista solidifica o discurso da ineficácia e incompetência, voltando a sugestionar mais repressão, justamente para sanar a "ineficiência" anterior. Nos dizeres de Adorno,

\begin{abstract}
A obsessão punitiva de nossa sociedade contemporânea, materializada nas chamadas "demandas por ordem social", explica-se justamente pelo modo de funcionamento da sociedade de risco que edifica toda uma imensa e resistente superestrutura de prevenção e segurança (através da proliferação das sociedades de seguro e dos mecanismos de vigilância privada) para fazer face aos medos, perigos e ameaças que tornam a vida humana, social e intersubjetiva, absolutamente incerta (ADORNO, 1998, p. 42).
\end{abstract}

Adorno (2003; 2008) relaciona medo e criminalidade ao traçar o distanciamento existente entre o sentimento subjetivo de insegurança e o risco objetivo. Nesse aspecto, acrescenta o autor que, embora as pesquisas fossem reflexo também de um aumento da criminalidade e da violência, parte da mídia eletrônica contribuiu para fomentar os sentimentos coletivos de medo através de seus relatos espetaculares cotidianos. A relação entre mídia e sensação de insegurança também é apresentada por Zaluar (1998). Segundo a autora, o espaço conquistado pela violência na mídia, nos últimos anos, não fugiu às ambivalências que caracterizam os meios de comunicação hoje existentes. Os veículos de informação - que representam um discurso de seriedade e verdade para grande parte da população - encobrem, através do discurso da violência, "qualquer acontecimento ou problema visto como socialmente ruim ou ideologicamente condenável, resultando disso a confusão com a desigualdade social, a miséria e outros fenômenos” (ZALUAR, 1998, p. 247). O pensamento da autora confirma a percepção de que o crime no Brasil aumentou significativamente a partir dos anos 80 , sendo que a mídia, por conferir maior visibilidade aos crimes violentos, acaba por reforçar a sensação de medo nas populações das grandes cidades. Zaluar (1998), também apresenta uma relação entre as altas taxas de criminalidade e o impacto causado pelo processo de modernização no país.

Segundo Carvalho (1995), existe uma grande parte da literatura produzida sobre a violência urbana brasileira que privilegia a criminalidade em suas conexões com o processo de modernização do País.

Segundo essas análises, a escalada da pobreza e os níveis de desigualdade que resultaram do descaso do Estado em implementar políticas distributivas mais progressivas ao logo do período de crescimento econômico seriam fatores responsáveis pela ampliação das taxas de conflito no Brasil. Por extensão, nossas grandes cidades estariam condenadas a viver sob o signo da violência, uma vez que contradições do modelo de modernização excludente têm gerado, ali, seus piores 
efeitos, tornando-se cenários de uma crise social permanente. Proliferaram, então, sob esse enfoque, os estudos sociológicos que, desde meados dos anos 70, procuram analisar o crescimento da criminalidade violenta em cidades tão diferentes quanto as do Rio de Janeiro, Belo Horizonte ou São Paulo. (CARVALHO, 1995, p. 55).

Garland (2008), ao analisar as alterações ocorridas a partir dos anos 1970 nos EUA e no Reino Unido, acena para a relação existente entre a expansão da criminalidade e os impactos da modernidade tardia. Segundo o autor, o espaço social tornou-se mais anômico, menos supervisionado, fatores estes agravados pelo boom do consumo, que colocou em circulação bens de alto valor, de forma a aumentar as oportunidades para o crime, além de ocorrerem maior mobilidade de pessoas e menor controle. O individualismo, o fim da definição do ser humano como um ser social e o desfazimento das instituições historicamente aceitas geram, nos dizeres de David Garland (2008, p.192), o afrouxamento dos laços de solidariedade entre os grupos. Neste sentido, reconhece o autor que o processo da pósmodernidade gerou distensão social, afrouxamento dos controles orgânicos, produzindo uma sociedade mais vulnerável, aberta, permeável e capaz de gerar mais oportunidades para a vida criminal. $\mathrm{O}$ déficit de controle e a maior tolerância penal têm como consequência a sensação de anomia e insegurança.

\footnotetext{
Esta correlação entre mudanças sociais da pós-modernidade e elevadas taxas de criminalidade não foi mera coincidência. A explicação mais provável para o rápido e constante aumento, em âmbito nacional, é de natureza social estrutural, apontando para parâmetros comuns ao desenvolvimento social. A despeito de consideráveis variações de lugar para lugar, em vários tipos de crimes, e apesar do impacto de diferentes regimes de controle social e legal, as evidências sugerem fortemente um liame causal entre a chegada da pós-modernidade e a crescente suscetibilidade da sociedade do crime. (GARLAND, 2008, p.203).
}

De acordo com Garland (2008, p.203), o impacto da pós-modernidade sobre o número de crimes foi multidimensional, tendo repercutido em quatro pontos principais: maiores oportunidades para a prática de crimes; controles situacionais reduzidos; aumento da população em situação de risco e redução da eficácia dos controles sociais e individuais, como consequência das mudanças na ecologia social e nas normas culturais.

No livro a "Cultura do Controle", David Garland analisa as dinâmicas das mudanças na pós-modernidade no século XX (2008, p.184/201), correlacionando tais alterações sociais com o aumento da criminalidade, bem como com a criação de uma cultura do controle, responsável pela erosão do discurso "lei de ordem". Embora tenha como objeto de pesquisa prioritariamente as sociedades Britânica e Norte-americana, o autor aponta alguns eixos de transformações da contemporaneidade que, fixados em prismas econômicos, sociais, culturais 
e políticos, evidenciam uma nova configuração às respostas ao crime. $\mathrm{O}$ argumento central do livro auxilia na compreensão da obsessão securitária da modernidade e sua relação com as novas formas de respostas ao crime.

Apesar da especificidade do campo escolhido pelo autor, Nascimento (2008), quando da apresentação à edição brasileira, nos aponta o porquê da leitura da obra auxiliar na análise da realidade brasileira e latino-americana.

\begin{abstract}
O motivo fundamental que recomenda a leitura da presente obra é que a análise da realidade britânica e, sobretudo, norte-americana constitui, de certa forma e em certa medida, a análise da realidade brasileira e latino-americana. Quem almeja entender por que o Brasil possui cada vez mais pessoas presas encontrará no exemplo dos EUA, o país que proporcionalmente mais encarcerou seres humanos no planeta, similitudes perturbadoras. Que quiser entender por que os meios de comunicação têm, com o passar do tempo, dedicado atenção crescente à questão criminal, perceberá que estamos percorrendo um caminho já trilhado antes. Quem já se deu conta da segmentação do espaço público e, dentro desta, da segregação de certos grupos, identificará as raízes deste processo urbano em aceleração nas práticas e ideologias atualmente vigentes nos EUA, na Grã-Bretanha e em outras democracias ocidentais. Quem, por fim, buscar entender os motivos para o assustador número de pessoas mortas em razão do crime ou de sua repressão, descobrirá que a semente do genocídio atualmente em curso nos centros urbanos brasileiros foi primeiramente plantada nos guetos das duas potências mundiais acima referidas - com absoluto protagonismo dos EUA, cuja "guerra contra as drogas" se encarrega de avultar suas estatísticas neste setor. (NASCIMENTO, 2008, p. 08).
\end{abstract}

Seja real ou percebido, o aumento da criminalidade nas ruas tem consequências nos planos simbólicos, econômico e político, sendo uma das preocupações centrais das populações metropolitanas brasileiras. As cidades contemporâneas não conseguiram cumprir a utopia liberal de liberdade e paz, perdendo civilidade, segurança, tato e confiança - velhas virtudes cívicas. As ameaças à segurança quebram o equilíbrio das tensões em que se monta a paz social, vindo a alimentar ciclos viciosos de violência (ZALUAR, 1998).

\begin{abstract}
As cidades, hoje, têm suas imagens tomadas pela deteriorização da qualidade da vida urbana, em que o temor da vitimização, tanto quanto a experiência direta dela, desmonta os operadores simbólicos com os quais se praticam os jogos sociais (....). Nos anos 90, a generalização de imagens da cidade como um ambiente violento e os sentimentos de medo e insegurança dela decorrentes passaram a fazer parte do cotidiano dos seus moradores (ZALUAR, 1998, p. 252).
\end{abstract}

No plano político, o aumento da criminalidade demanda do poder público novas formas de pensar a segurança pública, focadas em estratégias capazes de manter a confiança da população nas instituições. Segundo Soares (2005, p.28), “Os eleitores não querem mais saber se o problema é federal, estadual ou municipal. Querem soluções. Desejam optar entre 
propostas viáveis, práticas e urgentes”. Tal análise se alinha com a percepção de Barreira (2004, p. 77), para quem

os problemas ligados à área da segurança pública são politizados à medida que a legitimidade dos governos é predominantemente determinada por sua capacidade de manter a ordem e uma possível paz pública. Em outras palavras, a "presença" ou a "ausência" do governo são avaliadas e mensuradas, no imaginário da população, pela capacidade de manter a ordem e a segurança pública. (BARREIRA, 2004, p.77).

Em consequência, novos formatos organizacionais e institucionais surgem imbuídos de uma nova concepção de segurança pública. O discurso de ampliação do papel do município na área de segurança pública se fortalece e é potencializado pelo agravamento do quadro e ao desconforto da sociedade com a tradição do imobilismo municipal. Em um contexto em que as delimitações constitucionais e o discurso da ausência de responsabilidade deixam de satisfazer o eleitorado, a segurança pública entra na agenda municipal.

\section{PARADIGMAS DE SEGURANÇA NO BRASIL: DA DEFESA DO ESTADO À SEGURANÇA CIDADÃ. PARA COMPREENSÃO DO PRESENTE, UM RETORNO AO PASSADO}

O objetivo não é pensar historicamente o passado, mas sim, através da história, repensar o presente. (Garland, 2008)

Até o momento, buscou-se demonstrar como as discussões atuais sobre a efetividade das políticas de segurança pública podem ser percebidas como decorrência do aumento da percepção de insegurança e dos índices de criminalidade nas últimas décadas. No entanto, Freire (2009) sinaliza que a melhor compreensão da dinâmica atual da violência e as alternativas públicas disponíveis para seu enfrentamento perpassam pela reflexão sobre o histórico das políticas de segurança no país. As diversas formas de atuação e configuração percebidas em determinado local e períodos se relacionam diretamente aos conceitos e paradigmas que atuam como base para a formulação das políticas públicas de segurança.

Desta forma, a busca pelo conhecimento das condições históricas passa a ser o método para a percepção de como as políticas de segurança pública adquiriram suas características atuais, a clamar, inclusive, pela inserção do Município no debate. Ladeando a metodologia utilizada por Garland (2008) para explicar como as respostas criminológicas assumiram as feições contemporâneas, o que ele chama de "Cultura do Controle", a 
orientação da busca histórica estará focada mais por uma preocupação crítica de entender o presente do que por uma preocupação histórica de entender o passado. "O objetivo não é pensar historicamente o passado, mas sim, através da história, repensar o presente" (GARLAND, 2008, p. 43).

A existência de distintos paradigmas que determinaram as formulações de políticas públicas de segurança no Brasil é sinalizada por Freire (2009). Segundo a autora, a existência de visões de mundo compartilhadas, em determinados períodos, influenciam a forma de pensar de determinado grupo e, consequentemente, a produção científica e a formulação de políticas públicas. A identificação destes paradigmas é importante "para melhor conhecer os objetivos dos formuladores de políticas e os resultados que estas podem trazer para a sociedade". (FREIRE, 2009, p. 49).

De acordo com seus objetivos e estratégias, a autora apresenta três paradigmas na área da segurança, a partir de um recorte temporal das últimas cinco décadas. Esta forma de sistematização influenciou a atuação estatal e a percepção da sociedade sobre o tema no período mencionado. Os paradigmas identificados como Segurança Nacional, Segurança Pública e Segurança Cidadã, a seguir apresentados, são essenciais para a compreensão dos discursos oficiais sobre segurança pública no Brasil e, consequentemente, para a melhor percepção dos elementos centrais da discussão sobre a participação do Município na Segurança Pública.

Indicando, como marco temporal, o último período ditatorial vivenciado no Brasil, Freire (2009) apresenta três paradigmas de Segurança Pública, identificáveis ao longo de nossa história. Por paradigma, a autora entende o conjunto de visões de mundo compartilhadas que influenciam a formulação de políticas públicas e a produção científica de determinada época.

O paradigma de "Segurança Nacional" relaciona-se diretamente à existência do período de Ditadura Militar percebido no Brasil de 1964 a 1985. Dentro desta perspectiva, as ações da área da segurança eram direcionadas para as defesas do Estado, da ordem política e social. Após a tomada do poder pelas Forças Armadas, o País vivenciou um período caracterizado pela supressão de direitos constitucionais - censura, perseguição política e repressão - destinado a impedir qualquer manifestação contrária à ordem política vigente. A supremacia inquestionável do interesse nacional - ditado por uma elite no poder - era, segundo Freire (2009), a lógica que fundamentava o uso da força para a preservação da ordem. 
A política de segurança do período de exceção, fundamentada na "Doutrina de Segurança Nacional e Desenvolvimento" - formulada pela Escola Superior de Guerra -, justificou a criação de órgãos repressivos, como o Serviço Nacional de Informação (SNI) e órgãos de informação das Forças Armadas. Dentro deste contexto, fortemente associado aos preceitos da primeira Constituição promulgada pelo regime militar em 1967, bem como pela emenda constitucional de 1969, as Forças Armadas ganham destaque como essenciais à execução da política de segurança nacional. “As Forças Nacionais, nesse contexto, emergiram como intérpretes da vontade nacional" (FREIRE, 2009, p. 51).

O rótulo de "inimigo interno" é um fator importante para o fortalecimento do regime, e todo cidadão que pudesse atentar contra a vontade nacional passa a ser suspeito. A prioridade inicial dada ao inimigo externo - o comunismo - começa a ser direcionada para qualquer indivíduo contrário à ordem vigente. O discurso do inimigo - ameaça constante à segurança do Estado e interesses nacionais e coletivos - torna-se justificativa para o recrudescimento das estratégias bélicas de controle social, que visam ao fortalecimento e à manutenção dos interesses dos que estão no poder.

No período ditatorial, cria-se um novo criminoso, o revolucionário, que demanda pesados investimentos direcionados à formulação de uma "nova polícia" capaz de imobilizálo. A criação de um "novo criminoso", neste contexto, pode ser percebida como uma forma de gerir ilegalidades para satisfazer os anseios de um determinado momento político. A instrumentalização da delinquência - ilegalidade dominada - é um agente para a ilegalidade dos grupos dominantes (FOUCAULT, 2010). A utilização política dos delinquentes, sob a forma de "inimigos do Estado" é um instrumento para a ilegalidade que o próprio exercício do poder atrai para si. Segundo Foucault (2010), enquanto a oposição jurídica ocorre entre a legalidade e práticas ilegais, a oposição estratégica ocorre entre ilegalidades e delinquência. $\mathrm{O}$ processo de constituição de delinquência-objeto - ilegalidade isolada e fechada - não teria sido possível sem o desenvolvimento dos controles policiais.

Assim, uma atuação do Estado incisivamente repressiva, por meio das Forças Armadas, alinha-se com um conceito de "Segurança Nacional" definido "como a habilidade de um Estado em garantir, em determinada época, a obtenção e manutenção de seus objetivos nacionais, apesar dos antagonismos ou pressões existentes ou potenciais". (FREIRE, 2009, p.51).

Conceitualmente, o paradigma "Segurança Nacional" foi superado por uma nova ordem constitucional que se dizia mais apta a assegurar e proteger os direitos e garantias 
individuais. A Constituição Federal de 1988 rompe formalmente como o regime autoritário até então vigente e, ao menos retoricamente, reconhece no cidadão a centralidade das preocupações do Estado. É um diploma normativo fortemente influenciado pelo discurso da universalização dos direitos humanos que, ao se fortalecer no plano internacional através da Declaração Universal dos Direitos Humanos da ONU, em 1948, passou a influenciar políticas governamentais no Brasil, após a década de 1990 (MESQUITA, 2009).

Apesar do reconhecimento de que, no plano conceitual, a doutrina da "Segurança Nacional" foi superada pela nova constituição, recorrentes são os estudos que apontam para uma superação apenas "formal” deste paradigma. Tal fato estaria relacionado à manutenção das estruturas autoritárias das instituições policiais que, no paradigma da "Segurança Pública”, são atores centrais dentro do campo. Segundo Kruchin (2013),

Para Choukr (2004, p. 3), “a superação formal do regime militar brasileiro transformou muito pouco a essência e o funcionamento das estruturas policiais (...) a Constituição Federal abrigou todas as estruturas policias já existentes". Outro autor que tratou do tema foi Jorge Zaverucha, (2008, p. 142) que afirma que a justiça de transição produziu um "híbrido constitucional", caracterizado por uma democracia baseada no voto, mas que mantém enclaves autoritários. (KRUCHIN, 2013, p. 42).

Segundo Carvalho e Silva (2011), o processo de democratização do Estado, após duas décadas de ditadura militar, em pouco conseguiu modificar o Estado penalizador, fundado na instituição da criminalização. Teoricamente, tem-se um Estado democrático, porém, no plano prático, ainda se vive em um Estado autoritário, principalmente nas questões relacionadas à segurança pública. Segundo Adorno (1996, apud Carvalho e Silva, 2011, p. 61),

\footnotetext{
No Brasil, a reconstrução da sociedade e do Estado democráticos, após 20 anos do regime autoritário, não foi suficientemente profunda para conter o arbítrio das agências responsáveis pelo controle da ordem pública. Não obstante as mudanças dos padrões emergentes de criminalidade urbana violenta, as políticas de segurança e justiça criminal, formuladas e implementadas pelos governos democráticos, não se diferenciam grosso modo daquelas adotadas pelo regime autoritário. A despeito dos avanços e conquistas nos últimos anos, traços do passado autoritário revelam-se resistentes às mudanças em direção ao Estado democrático de Direito.
}

Apesar de a Constituição Federal de 1988 ter marcado a institucionalização do processo de transição para a democracia, em que os órgãos responsáveis pela manutenção da ordem pública passam a ter a necessidade de atuarem de acordo com princípios democráticos, Carvalho e Silva (2011) afirmam que os resquícios do período ditatorial permanecem encravados nas práticas policiais e, desta forma, podem ser obstáculos para a institucionalização de um novo arcabouço organizacional e administrativo dos órgãos 
incumbidos da segurança no país. O autoritarismo e o centralismo das instituições policiais são recorrentemente citados como obstáculos à efetivação de um novo paradigma de Segurança Pública.

Em que pese o fortalecimento do autoritarismo das instituições policiais durante o período ditatorial, Coutinho (1979), ao analisar o período vivido no Brasil, afirmou que o regime de exceção então vigente era "apenas" a expressão - extrema e radicalizada - de uma tendência dominante na história brasileira. O reconhecimento do caráter elitista e autoritário que assinalou toda a evolução política, econômica e cultural do Brasil, mesmo em seus breves períodos “democráticos", seria essencial para a compreensão dos enclaves autoritários percebidos em nossa sociedade. Desta forma, alguns apontamentos históricos sobre as instituições policiais no Brasil - as quais sempre tiveram um papel central nos debates sobre a segurança pública - visam auxiliar no entendimento dos fenômenos ocorridos atualmente.

A força policial, enquanto artefato do Estado Moderno, data dos fins do século XVIII e início do século XIX na Europa. No Brasil, a criação de uma polícia profissional e uniformizada, primeiramente no Rio de Janeiro e depois nas capitais provinciais, foi essencial para a transição gradativa do Brasil colônia ao Brasil Nação. Holloway (1997) afirma que a criação da Intendência Geral da Polícia em 1808, bem como o Código Criminal de 1830, foi um marco de superação do regime colonial, direcionando o Brasil rumo à autonomia.

A Intendência Geral da Polícia da Corte, que tinha por base o modelo francês introduzido em 1760, foi criada com a transferência da família real para o Brasil. Tinha por finalidade a manutenção da ordem pública, vigilância da população, investigação de crimes e captura de criminosos. A criação de uma força policial de tempo integral, organizada militarmente e com ampla autoridade para manter e perseguir criminosos, também foi fruto da vinda da família real. A Guarda Real, criada em 1809, cuja autoridade emanava do Monarca, mostrava sua ambiguidade na própria forma de seu financiamento, o qual era obtido através de taxas, empréstimos privados e subvenções dos comerciantes locais e proprietários de terras. O sistema de açoites, que evidenciava a interdependência das relações entre polícia, senhores e escravos, passou a ser também importante engrenagem para a subsistência do sistema, após a extinção dos capitães do mato.

A contradição imanente advinda do laço de reciprocidade entre a fonte da autoridade do Estado e a elite econômica é apontada por Holloway (1997) como um dos exemplos das relações mais gerais que explicam parte do conservadorismo das instituições políticas do Brasil e do Estado. As instituições policiais estabelecidas no Rio de Janeiro após 1808, com a 
eliminação dos capitães do mato, assumiram a tarefa antes realizada por eles de apreensão dos escravos fugitivos, atividade esta que se tornou principal categoria específica da atividade policial. A modernização do sistema de caça aos escravos fugitivos deu maior eficiência à solução do problema e o colocou sob o controle do Estado, fortalecendo a percepção do Estado como único detentor do monopólio legítimo da força.

Com a eliminação dos capitães-do-mato na década de 1820, o controle da população escrava urbana passou a ser cada vez mais compartilhado pelos senhores e o Estado. Na década de 1820, as autoridades policiais continuavam a aplicar o açoite corretivo a pedido dos senhores de escravos, cobrando uma taxa mínima de 160 réis por centenas de golpes, mais 40 réis por dia para cobrir os custos de subsistência, sem fazer perguntas sob o suposto delito. O serviço de açoite deixa de ser apenas um serviço disciplinar prestado pelo Estado, mas indispensável à própria manutenção do sistema, em um contexto, como o do Rio de Janeiro, em que a escravidão, no século XIX, é tão importante para as relações econômicas e a estrutura de classes da sociedade brasileira. O sistema de açoites evidencia claramente o relevo do papel do Estado como instrumento da classe dominante, atendendo as necessidades de controlar, por meio da violência física, os que forneciam a força muscular de que dependia a economia (HOLLOWAY, 1997, p. 64).

Os membros da guarda do Rio de Janeiro, que tinham por finalidade a manutenção da "tranquilidade pública" e outras obrigações de ordem civil, eram comandados por Paulo Fernandes Vianna, intendente da Guarda, que utilizava seus amplos poderes para financiar a instituição. A Guarda passou a perseguir vadios e ociosos - geralmente escravos - que eram encontrados nos arredores da cidade, enquanto confraternizavam, bebiam e dançavam.

\begin{abstract}
A meta era reprimir e subjugar, manter um nível aceitável de ordem e tranquilidade que possibilitasse o funcionamento da cidade no interesse da classe que elaborou as regras e criou a polícia para fazê-las cumprir. Tudo o que a guarda real desejava, já no seu nascedouro, era infundir o terroro nos corações ociosos, vadios e escravos racalcitrantes (HOLLOWAY, p.50).
\end{abstract}

A guarda, que estabeleceu padrões característicos de força policial, era composta por praças oriundos das classes sociais mais baixas, originalmente alvo da repressão policial. Seus hábitos expressavam a violência e truculência de uma sociedade escravocrata em geral. A organização militar da instituição permitia que sua força coercitiva fosse controlada pela disciplina, canalizada pela hierarquia e dirigida para alvos específicos, tidos como inimigos. Os inimigos da polícia do Rio de Janeiro, segundo Holloway (1997), eram os que violavam as regras de comportamento impostas por uma elite política que criou a polícia e dirigia sua ação. A utilização de conceitos militares para entender a polícia do Rio de Janeiro permite a compreensão da concepção da instituição, bem como seu funcionamento. A polícia era um 
exército permanente que travava uma guerra social contra os adversários que ocupavam o espaço a seu redor.

\begin{abstract}
O contato com o inimigo adivinha de ações guerrilheiras dos bandos de capoeira, de atos subversivos como fugir ao controle de seu dono e recusar-se a trabalhar, e de uma infinidade de pequenas violações individuais, que iam do pequeno furto ao atrevimento de ficar na rua após o toque de recolher (...). Pode-se ver esse exército de concentração de força como defensivo, visando proteger as pessoas que fizeram as regras, possuíam propriedade controlavam instituições públicas que precisavam ser defendidas. Mas também se pode vê-lo como ofensivo, visando a controlar o território social e geográfico - o espaço público da cidade - subjugando os escravos e reprimindo as classes inferiores livres pela intimidação, exclusão ou subordinação, conforme as circunstâncias exigissem". (HOLLOWAY, p. 50-51).
\end{abstract}

A coerção e sujeição se faziam necessárias para alcançar o nível de ordem e tranquilidade que os criadores das leis e polícia almejavam. Os atos de insubordinação dos escravos e classes inferiores eram enfrentados por um novo aparato policial, concebido para reprimir comportamentos inaceitáveis pelos detentores de poder. Percebemos, assim, que desde a época do Brasil colônia, o autoritarismo, a truculência e o padrão oligárquico já se encontravam presentes nas instituições incumbidas de prestarem "segurança pública”, modelo esse que se disseminou ao logo da história.

Transformar escravos e classes inferiores em delinquentes passa a ser uma forma de controle social. Segundo Foucault (2010), em sua obra Vigiar e Punir, através do "combate" à ilegalidade, reforça-se o próprio poder do Estado.

\footnotetext{
Mas a vigilância também de meios e de grupos considerados como perigosos pelos espias ou indicadores, que são quase todos antigos delinquentes, controlados como tais pela polícia: a delinquência, objeto entre outros da vigilância policial, é um dos instrumentos privilegiados dessa mesma vigilância (FOUCAULT, 2010, p. 266).
}

No Brasil Império, podemos observar uma maior estruturação das polícias brasileiras. A Guarda Nacional do Império foi criada em 1831, sendo que seu efetivo era formado somente por cidadãos eleitores. Tal restrição, somado ao caráter censitário do direito de voto previsto na Constituição Imperial de 1824, pode auxiliar na compreensão, segundo Mariano (2004), do padrão oligárquico e autoritário da corporação policial brasileira. Os não eleitores, maioria na população, eram os excluídos contra os quais se daria a ação do aparelho repressor.

A Constituição de 1824, outorgada por Dom Pedro I, apresenta-se historicamente como o primeiro texto legal estruturante de um Brasil independente. Vigendo durante todo o período do Império, instituiu a Monarquia Constitucional e o Estado Unitário, concentrando 
rigorosamente toda a autoridade política na capital. O Poder Moderador, personificado na mão de um Imperador sagrado, inviolável e totalmente irresponsável pelos seus atos, é a chave da organização política do Estado. Apesar da formação de uma Assembleia Constituinte em 1822, Dom Pedro I, apoiado pelas forças militares, dissolveu a constituinte e promoveu a prisão de vários legisladores. Ao justificar as prisões, Dom Pedro I (apud VILLA, 2011, p.09), afirmou: “As prisões agora feitas serão pelos inimigos do Estado consideradas despóticas. Não são. Vós vedes que são medidas das polícias próprias para evitar a anarquia e poupar as vidas desses desgraçados, para que possam gozar ainda tranquilamente dela e nós de sossego". Assim, não há como desvincular o autoritarismo e centralização do poder político da ação da Guarda Nacional, que passa a ser instrumento para manutenção dos poderes do Imperador.

A Constituição de 1891 consolidou a República e, ao instituir a forma federativa de Estado, permitiu a centralização do sistema de segurança pública nos estados federados, antigas províncias. No entanto, a lógica autoritária da segurança no país não conseguiu ser rompida, inclusive porque não houve uma desvinculação entre Forças Armadas e Forças Policiais. Nesse sentido, é ilustrativa a seguinte citação:

\footnotetext{
Em março de 1906, chegou à capital de São Paulo a Missão Francesa, chefiada pelo coronel Paul Balagny, solicitada pelo governo paulista, que resolvera dar treinamento de Exército aos componentes da Força Pública, cujo efetivo crescia: começara a previsão de 3.940 homens, em 1891, e chegou a 14.079, em 1924 (MARIANO, 2004, p.23).
}

Por fim, uma breve exegese da formação da Polícia Militar no Brasil nos aponta para o Decreto-Lei $\mathrm{n}^{\circ}$ 667, de 02 de julho de 1969, que, durante o governo do Presidente Costa e Silva, teve por finalidade a reorganização das Polícias Militares e Corpos de Bombeiros dos Estados e Distrito Federal. A previsão expressa no art. $1^{\circ}$ de que o controle e a coordenação das Polícias Militares seriam feitos pelo Ministério do Exército evidencia a inexistência de solução de continuidade entre Forças Armadas e Segurança Pública. Mariano (2004) afirma que, da fusão entre as extintas guardas civis até então presentes em 15 estados da Federação e a Força Pública, originou-se a Polícia Militar, influenciada diretamente pelo Exército.

As forças policiais - criadas para preservação dos interesses das elites representadas pelo Estado - foram estruturadas através de uma lógica autoritária e centralizadora, características estas que, reforçadas durante o último período militar brasileiro, se mantiveram, inclusive no âmbito legal-normativo, até o fortalecimento do movimento de reabertura democrática no Brasil. 
As políticas públicas promovidas pelo Estado brasileiro até o início dos anos 1980 , caracterizavam-se pela “(...) centralização decisória e financeira na esfera federal (...), pela fragmentação institucional (...), pelo caráter setorial(....)” e, principalmente, pela (...)exclusão da sociedade civil do processo de formulação das políticas, da implementação dos programas e do controle da ação governamental. (CARVALHO e SILVA, 2011, p.61/62).

A abordagem realizada reforçou a percepção de que a lógica que predominou no campo da Segurança Pública no Brasil ao longo da história consiste em políticas centralizadoras, fortemente marcadas pela concorrência de atribuições entre as forças armadas e órgãos policiais, bem como a utilização dos órgãos imbuídos pela gestão da segurança pública para a contenção dos delinquentes e/ou "inimigos" do Estado. Ao longo da história, o discurso da segurança, enquanto instrumento para salvaguardar a ordem pública, tornou-se mecanismo para o fortalecimento do próprio poder do Estado, através do monopólio da força e da utilização das normas jurídicas. Neste sentido, as regras do direito - enquanto mecanismos de saber-poder - produzem discursos verdadeiros, cujo conhecimento é indispensável para a compreensão dos próprios mecanismos do poder. "As normas jurídicas seriam os efeitos de verdade que esse poder produz, que esse poder conduz e que, por sua vez, reconduzem esse poder". (FOUCAULT, 2005, p. 28)

Retomando as análises dos paradigmas de segurança existentes no Brasil, percebemos que são recorrentes as inquietações sobre incapacidade de a chamada “Constituição Cidadã de 1988”, garantir a construção de uma política de segurança pública que se alinhe aos pilares democráticos. Esta descrença justifica-se, como vimos, pelo padrão centralizador e autoritário historicamente construído e fortalecido no campo da segurança no Brasil.

\footnotetext{
A Constituição Cidadã, promulgada no Brasil em 1988, não culminou, concomitantemente, na construção de uma política de segurança pública democrática por parte dos órgãos responsáveis, estabelecidos no "Estado Democrático de Direito". Por isso, as ações de controle da ordem pública tornaramse mais complexas na "ordem democrática" e a reorganização do aparelho estatal não resultou na imediata participação social na construção de política de segurança, necessária ao país. (CARVALHO e SILVA, 2011, p. 61).
}

No entanto, não há como deixar de reconhecer a mudança que a nova ordem normativa constitucional trouxe para o campo da segurança, permitindo, inclusive, a percepção de um novo paradigma a orientar as ações praticadas. Uma importante inovação da Constituição Federal de 1988 foi promover a separação entre as funções de polícia (art. 144 
da CF) e funções das Forças Armadas (art. 142 da CF), rompendo formalmente com a junção histórica entre as noções de Forças Armadas, Segurança Pública, defesa do Estado e defesa da sociedade. Neste sentido:

\begin{abstract}
É relevante destacar ainda que a perspectiva de Segurança Pública, ao suceder um paradigma no qual as Forças Armadas detinham a primazia da preservação da ordem, preocupa-se em diferenciar os papéis institucionais das polícias e do Exército. Essa separação de papéis transcrita no texto da Constituição é importante, pois destaca a distinção entre Segurança Pública e Segurança Nacional: a primeira é voltada à manifestação da violência no âmbito interno do país e, a segunda, refere-se a ameaças externas à soberania nacional e defesa do território. (FREIRE, 2009, p. 51).
\end{abstract}

No art. 144, a Constituição Federal define que a segurança pública deverá ser prestada pelos seguintes órgãos: Polícia Federal, Polícia Rodoviária Federal, Polícia Ferroviária Federal, Polícias Civis, Polícias Militares e Corpos de Bombeiros Militares. Apesar da inovação em relação ao paradigma anterior - ao destacar que a segurança é dever do Estado e direito e responsabilidade de todos -, Freire (2009) salienta que o legislador constitucional deixou de incluir expressamente o papel das outras instituições e/ou instâncias envolvidas. Desta forma, não há clareza no texto legal sobre a importância e/ou forma da atuação dos municípios.

Neste contexto, a prioridade da gestão da segurança pública passa a ser dos estados membros, através dos órgãos policiais. Apesar do otimismo reinante em relação à lógica da descentralização preconizada pela Constituição de 1988, no campo específico da segurança pública, Freire (2009) ressalta que a responsabilidade passa a ser prioritariamente dos estadosmembros, por serem estes os responsáveis pela gestão das polícias civil e militar. Desta forma, embora o texto constitucional não impeça a atuação de outras frentes, a centralidade das instituições policiais, até em virtude da redação do art. 144 da Constituição Federal, é inequívoca.

Através dos pontos acima apresentados, percebe-se que um dos aspectos principais dentro do paradigma de Segurança Pública é o deslocamento do controle do crime das forças armadas para as instituições policiais, bem como uma divisão rígida de competências no plano federativo, conferindo aos estados-membros grande autonomia para a concepção e execução de suas próprias políticas no setor (Silva, 2011).

Silva (2011) afirma que o panorama das políticas de segurança pública, até o início dos anos 2000, foi marcado por duas características basilares. Primeiramente, o governo federal tinha uma ação limitada, baseada na mobilização da Polícia Federal e Polícia 
Rodoviária Federal. Em segundo lugar, a centralidade das ações ostensivas nas instituições policiais e, consequentemente, nas agendas dos governos estaduais. A última afirmação reforça a indicação de que, dentro do paradigma de Segurança Pública, as instituições policiais possuem um papel central.

Através das considerações acima, é possível perceber uma mudança do foco na ação das políticas de segurança pública quando comparamos os dois paradigmas: "Segurança Nacional" e "Segurança Pública". Enquanto no primeiro as ações eram voltadas para a manutenção da ordem pública, através da inocuização de condutas que representassem ameaças contra os interesses nacionais, no arcabouço da segurança pública as ações - que também visam à manutenção da ordem pública - se dirigem contra condutas tendentes a ameaçar a integridade das pessoas e o patrimônio. Assim, através das políticas de segurança, o governo passa a gerir questões diversas da população, ultrapassando-se a lógica da mera preservação do território.

Apesar da clara alteração paradigmática observada após promulgação da $\mathrm{CF} / 88$, as reinvindicações para a implementação de um modelo que superasse concretamente o modelo repressivo do período político anterior aparecem com mais ênfase na última década (KRUNCUIN, 2013). O gradual processo de redemocratização da sociedade e, principalmente, a percepção da natureza multicausal da violência - a merecer diversas e criativas formas de atuação no campo das políticas públicas de segurança - evidenciam, no contexto brasileiro, o processo de construção da perspectiva que podemos denominar "Segurança Cidadã", referencial para o reconhecimento da importância do engajamento Municipal nas discussões e ações na área da segurança. Podemos situar a concepção de "Segurança Cidadã" dentro de um contexto de consolidação e fortalecimento das diretrizes da Constituição Federal.

Segundo Freire (2009), no Brasil, é possível perceber tentativas de aproximação deste conceito nos últimos anos. Um dos marcos apresentados é o Projeto de cooperação técnica "Segurança Cidadã", iniciado em 2003, fruto de uma parceria entre a Secretaria Nacional de Segurança Pública e as Nações Unidas, com a colaboração de técnicos colombianos. A autora afirma que esse projeto é o um marco, pelo menos conceitual, para a transição de um novo paradigma de segurança no país, que privilegia a característica federativa do Brasil, conferindo maior autonomia aos estados na condução das políticas de segurança em seus territórios. 
No Brasil, percebemos que, após a CF/88, algumas ações passaram a ser observadas em âmbito federal. Da percepção da necessidade de articulação entre os estados decorreu a criação, no âmbito do governo federal, em 1995, da Secretaria de Planejamento de Ações Nacionais de Segurança Pública, transformada, em 1997, em Secretaria Nacional de Segurança Pública - SENASP. Tal iniciativa do governo Fernando Henrique Cardoso (19942002) ocorreu conjuntamente com a construção do I Plano Nacional de Segurança Pública (O Brasil Diz não à Violência) e com a criação do Fundo Nacional de Segurança Pública (FNSP). (SILVA, 2011; CARVALHO e SILVA, 2011). No ano de 2000, surgiu o Plano Nacional de Segurança Pública - PNSP - voltado para o enfrentamento da violência no País.

O PNSP é considerado um marco teórico importante na propositura de uma política de segurança pública brasileira, cujo objetivo era articular as ações de repressão e prevenção à criminalidade no país. Apesar das criticas ao PNSP, principalmente em virtude da ausência dos resultados concretos esperados, Carvalho e Silva (2011) afirmam que, pela primeira vez “após o processo de democratização, emergiu a possibilidade de uma reorientação estratégica, com tratamento político-administrativo direcionado a colocar a questão da segurança pública como política prioritária do governo" (CARVALHO e SILVA, 2011, p.63).

Apesar de apontar para alguns defeitos técnicos do plano do governo FHC, Silva (2011) afirma que alguns de seus pontos abriram oportunidades relevantes para a abordagem de experimentos que depois se tornariam pontuais para o debate. Durante o $1^{\circ}$ governo no então presidente Luiz Inácio Lula da Silva, algumas mudanças foram aprimoradas, partindose da premissa de que o PNSP carecia de planejamento e gestão. Desta forma, a aposta é no bom diagnóstico da violência e da criminalidade como forma de alimentar as ações de prevenção orientadas e monitoradas por atores da segurança pública. A partir da elaboração do Projeto de Segurança Pública para o Brasil pela ONG Instituto da Cidadania - que serviu de base para o programa de governo durante a disputa eleitoral de 2002 - a ideia primordial era reformar as instituições de segurança pública e implantar o SUSP, que tinha como plataforma a atuação de forma articulada, por meio de políticas preventivas, principalmente voltadas para a juventude. (CARVALHO e SILVA, 2011).

Freire (2009) aponta que, inspirado no Sistema Único de Saúde, o Sistema Único de Segurança Pública visa articular as ações dos três entes federados, buscando aperfeiçoar o planejamento e trocas de informações para o êxito das ações na área. Apesar de não buscar a unificação, a lógica integrativa está estruturada em seis eixos: gestão unificada da informação; 
gestão do sistema de segurança; formação e aperfeiçoamento de policiais; valorização das perícias; prevenção e ouvidorias independentes e corregedorias unificadas. (FREIRE, 2009, p. 52). O modelo do SUS - Sistema Único de Saúde -, segundo Silva (2011), é um exemplo paradigmático no Brasil, ao demonstrar que a construção de "políticas nacionais", após a Constituição Federal de 1988, requer a elaboração de princípios e instrumentos de financiamento e estratégias de governança que estimulem a cooperação entre os vários entes federados.

O capítulo subsequente na construção do Plano Nacional de Segurança Pública é formado pelo PRONASCI. O Programa Nacional de Segurança Pública com Cidadania deslocou o equilíbrio de prioridades entre repressão e prevenção e valorizou a protagonismo dos municípios na elaboração e na execução do PNSP. Implementado no ano de 2007, o PRONASCI, além de instituir formalmente a concepção de Segurança Pública com Cidadania, objetivou a promoção e articulação sistêmica dos entes federados e da sociedade na promoção da Segurança Pública. Ponto relevante são o reforço e fomento à participação do Município, que passa a ser reconhecido como um agente construtor de políticas de segurança. Em sua estrutura, o Pronasci - instituído pela Lei 11530/2007 - apresenta-se como uma política de segurança pública baseada em princípios democráticos, interdisciplinares e humanitários, tendo em vista a participação da sociedade na construção de uma cultura de paz, a médio e longo prazo. Como decorrência do $1^{\mathrm{a}}$ Conferência Nacional sobre Segurança Pública (Conseg) desenvolvida pelo Governo Federal no ano de 2009, foram definidos alguns princípios estruturantes de uma política de segurança pública, que se alinhe com pilares democráticos e cidadão

\footnotetext{
Ser uma política de Estado que proporcione a autonomia administrativa, financeira, orçamentária e funcional das instituições envolvidas, nos três níveis de governo, com a descentralização e integração sistêmica do processo de gestão democrática, transparência na publicidade dos dados e consolidação do Sistema Único de Segurança Pública (SUSP) e o Programa Nacional de Segurança Pública com Cidadania (Pronasci), com percentual mínimo definido em lei e assegurando as reformas necessárias ao modelo vigente. (CARVALHO e SILVA, 2011, p. 65).
}

Os pilares elencados pelo então Ministro da Justiça Tarso Genro (SEGURANÇA e CIDADANIA, 2010) para a estruturação do PRONASCI - renovação da cultura da Segurança Pública; redefinição do papel da polícia e integração do Município como sujeito de políticas de segurança - são os aportes de sustentação de um novo paradigma de segurança no Brasil.

Na perspectiva da Segurança Pública, a descentralização alcança apenas o nível estadual. Com a Segurança Cidadã, nova ênfase é dada à gestão local da segurança e a atuação municipal passa a ser fundamental para a aplicação desse conceito. O mesmo ocorre com a participação social. Na Segurança Pública, já há a ideia de 
instauração dos conselhos, mas na Segurança Cidadã a participação social é central. O individuo é o centro da política e seu principal beneficiário, possuindo papel preponderante na gestão das políticas de segurança cidadã. A participação aqui extrapola os espaços institucionais dos conselhos, mas passa a ser vista como uma mudança cultural. (FREIRE, 2009, p. 56).

O processo de consolidação de um paradigma de segurança cidadã no Brasil ainda é um fenômeno em construção. Dentre as suas características, destaca-se a busca pela efetivação de políticas setoriais integradas em âmbito local. Um dos referencias deste novo paradigma foi o êxito das ações de prevenção e controle da criminalidade alcançado na Colômbia, a partir da segunda metade da década de 1990.

Bogotá, na Colômbia, se destaca e tem sido objeto de análise contínua em virtude de suas inovações em políticas públicas e gestão local da segurança. Sua experiência é destacada pela indicação da correlação entre a adoção pelos governantes de políticas locais de segurança pública e a melhoria da qualidade de vida dos habitantes da cidade. Da coincidência entre a queda nas taxas de criminalidade e administrações municipais que priorizavam, em suas agendas políticas, ações de redução de violência e insegurança, surgiram elementos para o reconhecimento do poder local como o arquiteto de mudanças estruturais na segurança municipal.

A conclusão de que a experiências de Bogotá influenciou o debate sobre as políticas de Segurança Pública no contexto brasileiro, é possível pela fala do então Ministro da Justiça Tarso Genro (SEGURANÇA e CIDADANIA, 2010) que, ao reconstruir as ideias discutidas para a articulação do Programa Nacional de Segurança Pública com Cidadania - PRONASCI -, afirma que o exemplo serviu como modelo para a equipe do Ministério da Justiça. O exemplo internacional de política de segurança pública objetivava orientar a construção de um projeto que conseguisse responder basicamente a três questões: como ter uma nova polícia que estabelecesse uma relação de proximidade com a comunidade; como integrar os municípios como sujeitos ativos de políticas preventivas e como renovar a cultura da segurança pública.

Segundo a publicação intitulada "Rumo a uma política integral de convivência e segurança cidadã na América Latina: Marco conceitual de interpretação - ação”, elaborada pelo Programa das Nações Unidas para o Desenvolvimento, entende-se por Segurança Cidadã Democrática

\footnotetext{
uma situação social livre de ameaças, em que as pessoas possam gozar plenamente de seus direitos e liberdades e exercê- los integralmente e na qual se conformam e se formulam políticas e mecanismos institucionais eficientes que tendem a administrar o conjunto de riscos ou conflitos (concretos ou previsíveis) que lesem a liberdade ou o gozo pleno desses direitos, mediante sua prevenção, controle ou repressão. (PNUD, 2007, p. 10).
} 
Tal material demonstra que a concepção de segurança cidadã parte da premissa de que a prevenção, o controle, a sanção e a repressão da violência e da delinquência são responsabilidade do Estado, sem detrimento, entretanto, das responsabilidades que cabem à sociedade civil. Desta forma, define-se a política de segurança cidadã

\begin{abstract}
como o conjunto de intervenções públicas realizadas por diferentes atores estatais e sociais voltados para a abordagem e a resolução daqueles riscos e conflitos (concretos ou previsíveis) violentos e/ou delituosos que lesem os direitos e as liberdades das pessoas, mediante a prevenção, o controle e/ou a repressão dos mesmos. Uma política eficaz deve ser o resultado de uma análise detalhada da situação, considerar metas de médio e longo prazo se compreender ferramentas ou instrumentos que englobem os diversos tipos de problemas que terá que enfrentar para prevenir e reduzir os fenômenos de violência e delinquência. (PNUD, 2007, p.10-11).
\end{abstract}

Percebe-se que na perspectiva apresentada, o foco de atuação das políticas de segurança pública é o cidadão. Assim, permanece a proteção à vida e à propriedade, como delineia o paradigma de segurança pública, porém a proteção avança rumo à plena cidadania, sendo a violência percebida como um dos fatores que inviabilizam sua efetivação. As políticas preventivas, bem como as integradas - capazes de mobilizar a participação social e os diversos entes federativos - ganham importância. É neste arcabouço conceitual e paradigmático que o município passa a ser reconhecido como um dos entes centrais na implementação e na gestão das políticas de segurança pública.

\title{
CONCLUSÃO
}

Após mais de duas décadas da promulgação da "Constituição Cidadã", em um contexto social em que a violência urbana passa por um processo de interiorização e torna-se uma das principais inquietações políticas e sociais, as políticas de segurança pública passam por novos formatos organizacionais que devem responder a um duplo interesse: atender aos ditames de uma sociedade "democrática" e "cidadã” e, principalmente, se mostrarem aptas a promoverem a segurança enquanto bem individual e coletivo. Dentro deste contexto, a segurança pública entra para agenda municipal como um dos pilares da estruturação de um novo paradigma de segurança - Segurança Pública Cidadã -, que afirma a importância da adoção de políticas setoriais integradas em âmbito local. 
O processo de descentralização das políticas de segurança pública - que como dito parte da premissa da importância da participação do ente municipal para os êxitos das ações ocorre simultaneamente a uma busca por novas estratégias para a contenção do aumento exponencial da violência urbana. Neste sentido, os novos discursos na segurança pública relacionam-se com a percepção trazida por autores, como Soares (2005) e Barreira (2004), de que a violência urbana também tem consequências no âmbito político.

O objetivo principal desta pesquisa foi compreender o processo de inclusão do município nos debates sobre a gestão das políticas de segurança pública dentro do contexto brasileiro atual. Da abordagem histórica surgiu a percepção de que tal discussão se alinha com o gradual processo de democratização percebido no Brasil, tendo com marco temporal a própria Constituição Federal de 1988. No entanto, estatutos normativos subsequentes, tais como Plano Nacional de Segurança Pública e Programa Nacional de Segurança Pública com Cidadania são instrumentos legais que, gradativamente, buscavam reforçar o ideal da descentralização também para as políticas de segurança pública.

A busca pela descentralização e, consequentemente, pela efetiva participação do município na gestão da violência urbana, contrapõe-se a lógica que predominou historicamente no campo da Segurança Pública no Brasil. A preeminência de políticas centralizadoras, fortemente marcadas pela concorrência de atribuições entre as forças armadas e órgãos policiais, bem como a utilização dos órgãos imbuídos pela gestão da segurança pública para a contenção dos delinquentes e/ou "inimigos" do Estado, são características que, embora fortalecidas durante o último período ditatorial, são percebidas no processo de construção das instituições policiais brasileiras.

A análise dos diversos paradigmas, bem como a compreensão do processo de hegemonia e centralidade das instituições repressoras no campo da segurança pública no decorrer da história brasileira, foi importante para a identificação dos possíveis obstáculos à consolidação efetiva de um paradigma de segurança pública cidadã no Brasil. Assim, a ruptura com o modelo de controle da violência pela força, bem como o reconhecimento da importância de novos atores centrais para a implementação das políticas públicas destinadas à gestão da criminalidade urbana, com destaque ao município, são essenciais para a consolidação de um modelo de segurança pública concebido sob o ângulo democrático. 


\section{REFERÊNCIAS BIBLIOGRÁFICAS}

ADORnO, S. Lei e ordem no segundo governo FHC. Tempo Social, v.15, n.2, p.103-140, Nov. 2003.

ADORNO,S.;LAMIM,C. Medo, violência e insegurança.In: LIMA,R.S.;PAULA, L. (Orgs.). Segurança Pública e violência: $O$ Estado está cumprindo seu papel? São Paulo: Contexto. $1^{\text {a }}$ Ed, 2008, p.150-171.

AlMEIDA, G.A; APOlinÁRIO, S.M.O.S. Direitos Humanos. São Paulo: Atlas, 2009.

ALVES, M. C. Gestão local e políticas públicas: os desafios do campo da segurança. Disponível em: < http://www.forumseguranca.org.br/storage/download//anuario_ii__gestao_local_e_politicas_publicas_-_os_desafios_do_campo_da_seguranca1.pdf $>$. Acesso em:05.ago.2015.

ANDRADE, V.R.P. A mudança do Paradigma Repressivo em Segurança Pública: reflexões criminológicas críticas em torno da proposta da $1^{\text {a }}$ Conferência Nacional Brasileira de Segurança Pública. Sequência. n.67, p.335-356, Florianópolis. dez/2013.

BARREIRA, César. Em nome da lei e da ordem: a propósito da política de segurança pública. São Paulo Perspec., São Paulo, v. 18, n. 1, p. 77-86, Mar. 2004 . Disponível em: $<$ http://www.scielo.br/scielo.php?script=sci_arttext\&pid=S0102-

88392004000100011\&lng=en\&nrm=iso>. Acesso em: 24 Jun. 2015.

BEATO, C.F. Crime e políticas sociais. Das políticas de Segurança Pública as Políticas de Segurança. O Brasil diz não à violência. Gabinete de Segurança Institucional. Brasil, 2002. p.09-20

BENGOCHEA. et al. A transição de uma polícia de controle para uma polícia cidadã. São Paulo em Perspectiva, v. 18 (1). p. 119-131, São Paulo. 2004.

BRASIL. Constituição (1988). Constituição da República Federativa do Brasil. Brasília, DF: Senado, 1988.

BRASIL, Lei $\mathrm{n}^{\circ} 11530$, de 24 de outubro de 2007. Institui o Programa Nacional de Segurança Pública com Cidadania - PRONASCI e dá outras providências. Brasília, DF. Disponível em: http:// www.planalto.gov.br.

BRASIL, Projeto de Lei $\mathrm{n}^{\circ} 3734$, de 23 de abril de 2012. Disciplina a organização e o funcionamento dos órgãos responsáveis pela segurança pública, nos termos do $\$ 7^{\circ}$ do art. 144 da Constituição, institui o Sistema Único de Segurança Pública - SUSP, dispõe sobre a segurança cidadã, e dá outras providências. Brasília, DF. Disponível em: http://www.camara.gov.br.

CARVALHO, V.A; SILVA, M.R.F. Políticas de segurança pública no Brasil: avanços, limites e desafios. Revista katál, v.14, n.1. p.59-67. Florianópolis. jan/jun.2011. 
CASTRO, J.D.C. Polícia Metropolitana de Bogotá: um modelo vitorioso da polícia da Colômbia. In: OLIVEIRA,F.B;ZOUAIN,D.M;RUEDIGER,M.A;RICCIO,V (Orgs). Desafios para a gestão pública de segurança. Rio de Janeiro: FGV.1 ${ }^{a}$ Ed, 2009, 255-

271.

COUTINHO, C.N. Notas sobre a Cidadania e Modernidade. Revista Ágora: Políticas Públicas e Serviço Social, Ano 2, nº 3, dez/2005 [1994].

A Democracia Como Valor Universal. [1979]. Disponível em: http://boletimef.org/biblioteca.

FOUCAUlT, M. Microfísica do Poder. Graal. Organização, introdução e revisão técnica Roberto Machado. 26ª ed. São Paulo, 2013.

. Vigiar e Punir: Nascimento da prisão. $38^{\circ}$ ed. Editora Vozes. Petrópolis 2010. Trad. Raquel Ramalhete.

Segurança, território, população. Curso dado no Collège de France (1977-1978). Tradução Eduardo Brandão. São Paulo: Martins Fontes, 2008.

. Em defesa da sociedade. Curso no Collège de France (1975-1976). Martins Fontes, 2005. Tradução Maria Ernantina Galvão.

FREIRE, M. D. Paradigmas de segurança no Brasil: da ditadura aos nossos dias. Revista Brasileira de Segurança Pública, São Paulo, Ano.3, 5 a Ed., p.100-114, ago./set.2009.

FREY, K.; CZAJKOWSKI, S. O município e a segurança pública: o potencial da governança democrática urbana. RAP, Rio de Janeiro. 39(2), p. 297-325, Mar/Abr.

2005 .

GARLAND, D. A cultura do controle. Crime e ordem social na sociedade contemporânea. Tradução André Nascimento. Editora Revan, 2008.

HOlloway, T.H. Polícia no Rio de Janeiro. Repressão e resistência numa cidade do século XIX. Tradução Francisco de Castro Azevedo. Rio de Janeiro: Fundação Getúlio Vargas, 1997 [1944].

KRUCHIN, M. K. Análise da introdução de um novo paradigma em segurança pública no Brasil. Revista Brasileira de Segurança Pública, São Paulo, v.7, n.1, p.40-56, fev/mar. 2013.

LENZA, P. Direito Constitucional Esquematizado. 13 ${ }^{\text {a }}$ ed. São Paulo: Saraiva, 2009. LIMA,R.S; PAULA, L. Introdução. In: LIMA,R.S.;PAULA, L. (Orgs.). Segurança Pública e violência: O Estado está cumprindo seu papel? São Paulo: Contexto. $1^{\text {a }} \mathrm{Ed}$, 2008, 
MARIANO, B.D. Por um novo modelo de polícia no Brasil: A inclusão dos municípios no sistema de segurança pública. 1.ed.São Paulo: Fundação Perseu Abramo, 2004.

MARTIN, G.; CEBALlOS, M. Bogotá: anatomía de una transformación. Políticas de seguridad ciudadana 1995-2003. Editorial Pontifícia Universidad Javeriana, Bogotá, 2004. Resenha de: GAVIRIA, M.R. Cultura e Segurança cidadã: em busca do controle da violência da Colômbia. Sociologias, Porto Alegre, ano 9, $\mathrm{n}^{\circ}$ 18, jul/dez.2007, p.316-335.

MENDES, G.F; BRANCO, P.G.G. Curso de Direito Constitucional. $7^{\mathrm{a}}$ ed.São Paulo: Saraiva, 2012.

MESQUITA,N.P. Segurança, justiça e direitos humanos no Brasil.In: LIMA,R.S.;PAULA, L. (Orgs.). Segurança Pública e violência: O Estado está cumprindo seu papel? São Paulo: Contexto. $1^{\text {a }}$ Ed, 2008, p.53-64.

MINAYO, Maria Cecília de S.; SOUZA, Edinilsa R. de. Violência para todos. Cad. SaúdePública, Rio de Janeiro , v. 9, n. 1, p. 65-78, Mar. 1993 . Disponível em: $<$ http://www.scielo.br/scielo.php?script=sci_arttext\&pid=S0102311X1993000100007\&lng=en \&nrm=iso>. Acesso em: 24 Jun. 2015.

MIRAGLIA.P. Os Municípios e a segurança pública.In: LIMA,R.S.;PAULA, L. (Orgs.). Segurança Pública e violência: O Estado está cumprindo seu papel? São Paulo: Contexto. $1^{\text {a }} \mathrm{Ed}, 2008$, p.89-99.

MUNIZ.J. Direitos Humanos na Polícia.In: LIMA,R.S.;PAULA, L. (Orgs.). Segurança Pública, violência: O Estado está cumprindo seu papel? São Paulo: Contexto. $1^{\text {a }}$ Ed, 2008, p.65-88.

NASCIMENTO, A. Apresentação à edição brasileira. In: GARLAND, D. A cultura do Controle. Crime e ordem social na sociedade contemporânea. Tradução André Nascimento. Editora Revan, 2008

SAPORI, L.F.; ANDRADE, S.C.P. Arranjos Institucionais e Políticas de Segurança Pública na Sociedade Brasileira. In: CRUZ, M.V.G.; BATITUCCI, E.C. Homicídios no Brasil. Rio de Janeiro: Editora FGV, 2007, p. 191-228.

PIOVESAN, F. Direitos Humanos: Desafios e perspectivas contemporâneas. Revista TST, Brasília, v.75, n.1, jan/mar. 2009.

PIOVESAN, F. Direitos humanos globais, justiça internacional e o Brasil. Revista Fundação da Escola Superior do Ministério Público do Distrito Federal e Território, Brasília, ano 8, v.15, jan/jun 2000, p. 93-110

RELATÓRIO FINAL DA $1^{\mathrm{a}}$ CONFERÊNCIA NACIONAL DE SEGURANÇA PÚBLICA, 2009, Brasília. 1 $1^{a}$ Conferência Nacional de Segurança Pública. Brasília: Ministério da Justiça, 2009. 156. Disponível em: http://www.ipea.gov.br.

SAPORI, L.F. Segurança pública no Brasil: desafios e perspectivas. Rio de Janeiro: Editora FGV, 2007. 
SEGURANÇA E CIDADANIA. Memórias do Pronasci: depoimentos ao Cpdoc. In:FERREIRA,M.M; BRITTO,A (Orgs.). Rio de Janeiro: FGV. 1ªed. 2010.

SILVA, J.C. Manutenção da ordem pública e garantia dos direitos individuais: os desafios da polícia em sociedade democráticas. Revista Brasileira de Segurança Pública. São Paulo, ano 5, ed. 8, p.78-89, fev/mar. 2011.

SOARES, L.E. Segurança municipal: sugestões para uma agenda mínima: In SENTOVIANNA, Oliveira. Instituições Políticas Brasileiras. Segundo Volume. Brasília: Senado Federal, 1999.

VILLA,M.A. História das Constituições Brasileiras. 200 anos de luta contra o arbítrio. Biblioteca do Exilado, 2011.

WAISELFISZ, J.J. Mapa da violência 2013: Mortes matadas por arma de fogo. Centro Brasileiro de Estudos Latino-Americanos. Flacso-Brasil.

WAISELFISZ, J.J. Mapas da Violência 2014: Os Jovens do Brasil. Rio de Janeiro: FLACSO, 2014. Disponível em:

<http://www.mapadaviolencia.org.br/pdf2014/Mapa2014_JovensBrasil_Preliminar.pdf>.

Acesso em:05.ago.2015

ZAVERUCHA, J. A Crescente Inserção das Forças Armadas na Segurança Pública. In: CRUZ, M.V.G.; BATITUCCI, E.C. Homicídios no Brasil. Rio de Janeiro: Editora FGV, 2007, p. 25-50.

ZALUAR, A. Pra não dizer que não falei do samba: os enigmas da violência no Brasil. In: SCHWARCZ, L.M. (Org.). História da Vida Privada no Brasil: Contrastes da Intimidade Contemporânea. v.4. Companhia das Letras, 1998. 